\title{
Cocktail of Food Science and Argumentation: Shaken or Stirred for Learning?
}

\section{Sibel Erduran}

University of Bristol, United Kingdom • sibel.erduran@bristol.ac.uk

\begin{abstract}
Food science like other domains of science poses challenges to teachers and learners. A significant challenge concerns the articulation in the learning environment of the evidence and justification for the knowledge claims made about food. Often such claims are based not on evidence but myth. What is the evidence that a potato will absorb excess salt in a soup or stew? Or that butter will spoil if not refrigerated constantly? Articulation of the evidence and justification necessitates the incorporation of the epistemic practices of food science in the learning environment. Epistemic practices are the cognitive and discursive activities that develop epistemic understanding understanding of the nature of knowledge including how knowledge production occurs. Argumentation, the coordination of theory and evidence, is an example epistemic practice that has grown as an area of interest in science education in the past two decades. Numerous studies have highlighted the importance of argumentative discourse in the acquisition of scientific knowledge and the development of habits of mind in science. The implication is that argumentation is a form of discourse that needs to be appropriated by learners and explicitly taught through suitable instruction, task structuring and modeling. In this paper, an example introduced to illustrate how argumentation can be contextualised in food science with concrete teaching and learning scenarios. The question is raised about whether the argumentation orientation poses a radical stir or it could be integrated into existing instructional frameworks in food science. A set of recommendations for the design and implementation of professional development provision are provided to enhance food science teachers' learning of epistemic practices of science including argumentation.
\end{abstract}

\section{Introduction}

There is a well known line from the J ames Bond film series that brings food science into popular discourse: "Shaken not stirred" ("James Bond", 2012). Bond is referring to his preference of vodka martini being shaken with ice rather than stirred with it. Nowadays connoisseurs agree that stirred martinis are actually superior to the shaken version. There are various potential claims that one could make to substantiate Bond's preference. It could be that shaking the martini gets aldehydes oxidised in a similar manner that red wine oxidises while it 'breathes.' Another possibility is that shaking a martini breaks down hydrogen peroxide in the drink thus changing the flavour. It is now understood that Ian Fleming was writing after World War II when grain was expensive and a lot of vodka was made of potatoes. Potato vodka shaken with ice dissipates oil making for a smoother drink.

What is the significance of this story for science education? First, it raises significant questions about how we are teaching students to substantiate the claims made about the natural world in science classrooms. What is the evidence that the stirred or shaken version of a vodka martini tastes better, to whom and why? School science is littered with similar claims that are often unsubstantiated with evidence from the point of view of the pupils: 
"Day and night are caused by a spinning Earth", "Photosynthesis generates oxygen' and "Matter is made of tiny indivisible particles." With respect to issues regarding food, school children as well as adults alike are surrounded by claims that are incorrect from a scientific standpoint: "potato will absorb excess salt in a soup or stew; butter will spoil if not refrigerated constantly; leaving an avocado pit in a pot of guacamole will prevent it from turning brown; and some foods contain negative calories."

A key aspect of science that would target the justification of claims with evidence is 'argumentation'. In the rest of this paper, a brief overview of argumentation in the context of science teaching, learning and teacher professional development is provided. Argumentation studies are relatively new in science education research, having emerged in the 1990s (Erduran \&J imenez-Aleixandre, 2012). The aim is to link existing aspects of our work in argumentation (e.g. Erduran \& Pabuccu, 2012; Erduran, 2012; Erduran \&JimenezAleixandre, 2012; Erduran, Simon \& Osborne, 2004) with food science concepts in order to promote an evidence-based approach to the teaching and learning about food.

\section{Theoretical Background}

Despites decades of educational reform, even graduates of science programmes are typically unable to provide reasons, evidence and justification for some of their claims about the natural world (Erduran, 2012). Engaging students in argumentation is important because it places the students in the position where they can begin to collect, interpret and evaluate evidence for the claims we make about natural phenomena. Is shaken martini really better tasting than a stirred one? How can we establish the validity of this claim? What evidence can we collect to do so? Engaging learners in the articulation of such questions means that science learning becomes aligned with how scientists themselves do science. Science is not about cookbooks where procedures are replicated mindlessly. Manipulation of variables for the sake of verifying already known outcomes - as is the case in the majority of school science investigations - is also not scientific in nature. Authentic scientific enquiries allow for the generation of evidence and justification of scientific knowledge in the classroom. They create room for students not only to generate and evaluate evidence but also to establish the criteria and standards by which to judge evidence in the classroom environment. Authentic scientific enquiries have argument at their core (Erduran, 2007). Yet, despite the increasing emphasis on argument in the science curriculum (e.g. Lavelle \& Erduran, 2007), the implementation of argumentation in actual classrooms remains a challenge.

There is substantial research on argumentation (e.g. Kuhn, 1993; van Eemeren et al., 1996; Perelman \& Olbrechts-Tyteca, 1969). However, research on argumentation in science education has typically concentrated on two main definitions of argument based on the work by Stephen Toulmin (e.g. Erduran, Simon and Osborne, 2004) and Douglas Walton 
(e.g. Walton, 1996; Ozdem, Cakiroglu, Ertepinar \&Erduran, 2013). While these two models have often been presented in contrast to each other, it is worthwhile to highlight that they actually address different aspects of argument and argumentation. Toulmin's framework, summarised in the diagram below, concentrates on the components of an argument (Toulmin, 1958), whereas Walton's schemes detail different types of arguments (Ozdem, Cakiroglu, Ertepinar \& Erduran, in press).

In Toulmin's scheme represented in Figure 1, an argument has three essential components: claim (C), data (D) and warrant (W). There are three components that account for other features of arguments: backing (B), modal qualifiers (Q) and rebuttals (R).

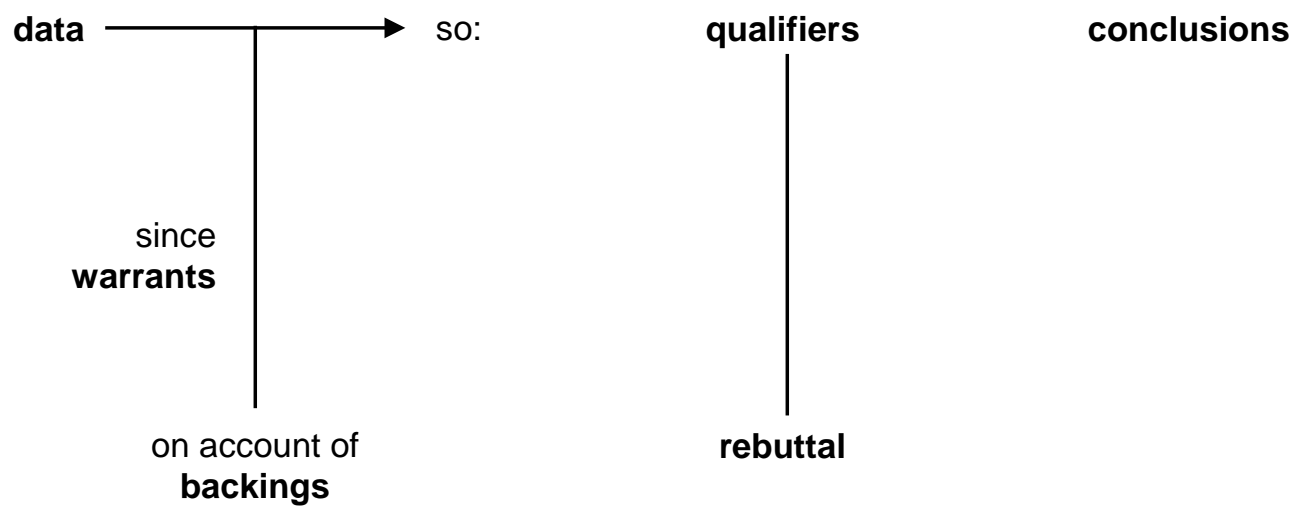

Figure 1. Toulmin's Argument Pattern (Toulmin, 1958).

- Claim: the statement, knowledge claim or conclusion that has to be supported or disproved.

- Data: observations, facts or experiments that are appealed to as a foundation for the claim, or in more general terms, which are used in order to evaluate a claim. In science education the term evidence has been used in some argumentation contexts: it should be noted that is not fully interchangeable with datum. In other analyses data and warrants are collapsed under the term evidence.

- Warrant: a statement that relates the claim to the data, in order to show that, taking these data as a starting point, the step to the claim or conclusion is a legitimate one.

- Backing: generalizations making explicit the body of knowledge or experience relied on to establish the authority or trustworthiness of the warrants.

- Modal qualifiers: indicate the strength conferred by the warrant; express the grade of certainty or uncertainty of an argument, for instance "probably", "for sure", "it depends".

In the next section, a potential use of the Toulmin's framework in the context of food science will be exemplified with implications for the design of pupil and teacher resources for secondary education. 


\section{Methodology}

Our research and development approaches on argumentation in science education have focussed on the design of learning environments and professional development programmes in order to faciliate the implementation of argumentation in everyday classrooms (e.g. Erduran \& Pabuccu, 2012; Erduran, Yee, \& Ingram, 2011; Erduran \& Yan, 2008). Based on the evidence from this research and development programme, an example activity is presented.

\subsection{Activities for pupils}

In order to address the arguments about whether or not adding potatoes to stew has any impact on how salty it is, an interesting and motivating story can be presented to learners as follows:

When Martin was making a beef stew, the phone rang and he went to answer it. Meanwhile, Amy who didn't know that Martin had already put some salt in the stew put some more. When Martin came back, he tasted the stew and found out that it tasted horrible and so salty! He had an idea that he could put some potatoes to absorb the excess salt. Amy however disagreed that adding any potatoes to the stew would make any difference. What do you think?

In order for pupils to engage with this scenario, they will need to be supported with some statements to help them begin the discussion. The following table includes statements that could be placed on cards and cut out to be distributed to pupils. Similar and extended set of statements can be produced. The aim is to get the pupils discuss, debate and engage in a group discussion in order to address the question in the scenario. The important aspect of this kind of an activity is that the pupils are expected not only to present their claim but also justify with evidence from these and other sources why their claim holds true. A further and more complex skill is the ability to refute the opponent's claim by using evidence to counter their evidence. The ability to provide rebuttals in a dialogic argumentation context has been argued to present a higher cognitive skill in our related work (e.g. Erduran et al., 2004). 
Table 1. Evidence statements.

A potato absorbs any liquid like a sponge absorbs water.

The concentration of salt in the potato is lower than in the liquid of the stew.

Potatoes contain salt.
Salt is distributed equally in a stew.

The potato has to be peeled to be able to absorb salt.

There is no reason why potatoes will suck away all the salt in the stew, they are not magical!

A potential argument that might emerge from this activity is represented in Figure 2 which follows the Toulmin's framework of argument.

\section{Potatoes to the rescue?}

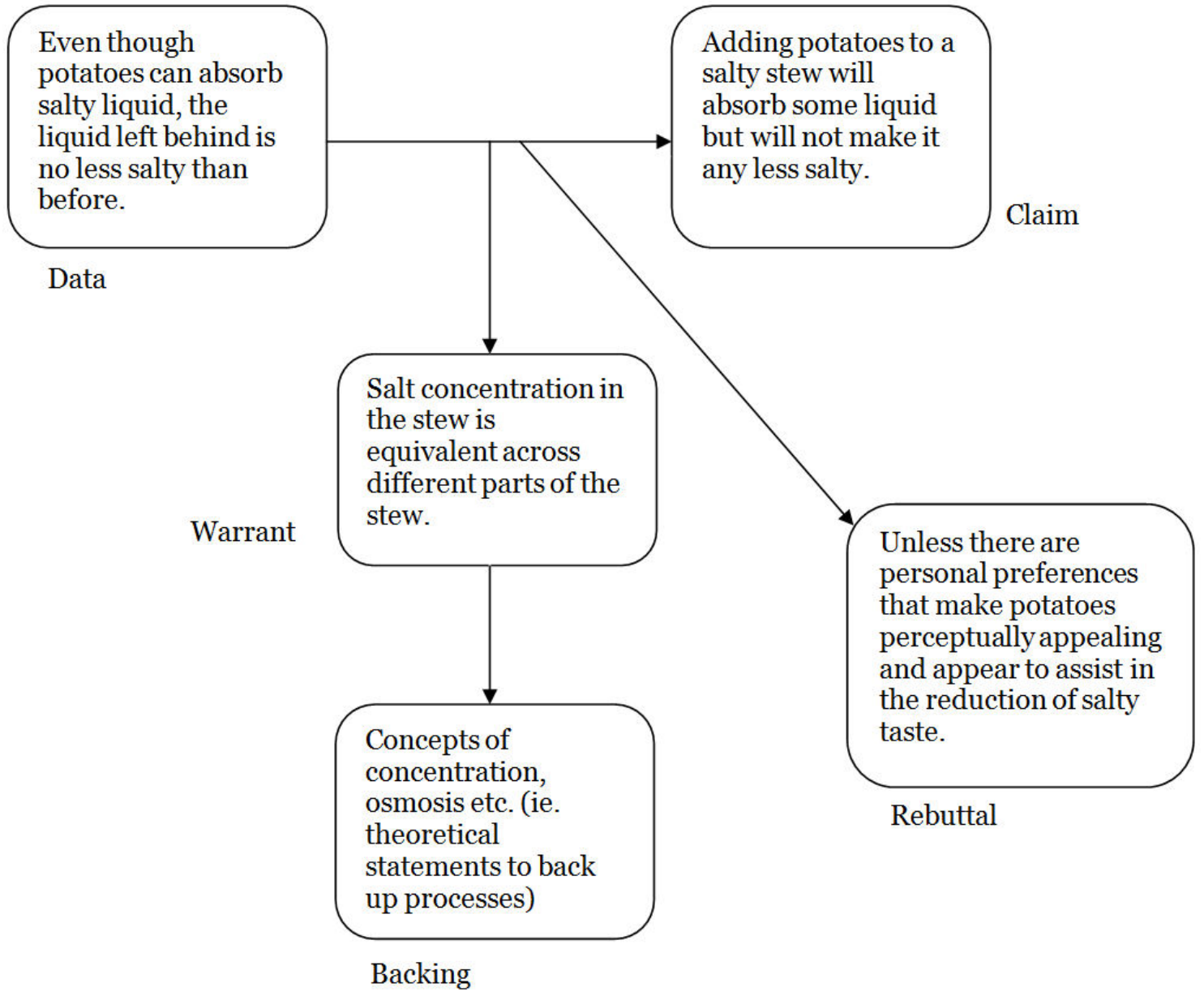

Figure 2. Example argument for the potato activity. 


\subsection{Model of Professional Development}

The design of activities that promote argumentation is necessary but not sufficient to ensure that argumentation will take place at the level of the classroom. Professional development of science teachers is pre-requisite if teachers are to pick up and teach a novel strategy that is not often encountered in their professional lives. There is a substantial body of research literature on professional development of science teachers. According to Supovitz and Turner (2000), a high-quality professional development programme should immerse participants in inquiry, questioning and experimentation in a collaborative manner. Our professional development projects (e.g. Erduran, 2012; Erduran, Yee, \& Ingram, 2011; Erduran \& Yan, 2009) have been guided by the principles of teachers' collaborative exchanges with peers and reflective inquiries into their own teaching. In particular, the professional development programme modelled the argumentation practices in the entire process from identifying a claim to make about own teaching to communicating and justifying such claims. The following were the overview of the components of design of the professional development agenda:

- Identifying a problem to investigate

- Negotiating and justifying choice of topic, pupils etc.

- Gathering and evaluating data

- School-based work including peer video-taping and pair conversations on data

- Selecting and justifying evidence

- Group selection of video and resource data

- Communicating knowledge

- Workshop presentations to peers; conference presentation by team

The next section will outline some of the outcomes of the professional development approach.

\section{Outcomes of Professional Development}

One of the outcomes of the professional development programme in our work has been a hightened argumentation among the teachers and reliance on evidence from the classroom, as the following quote illustrates:

T1: You know it's. . It didn't flow as well as I hoped it would. The barriers to talking seemed to still be there.

T2: Uhm, I don't, I don't know whether I agree coz having gone around and spoken to them, uhm, on an individual group by group basis...

T1: Yeah

T2: ...each group was very happy to tell me on camera...

T1: Yes.

T2: ... what they were doing and who was doing what and their strengths and all that kind of thing within the group, so they obviously had it worked out. 
In this lesson, $\mathrm{T} 1$ was making a claim about how she thought the lesson was not progressing well because the children were not talking enough. T2 disagreed and provided a rationale for why she was against this observation. She had videotaped T1's lesson and was able to point out that the pupils were indeed talking, contrary to the claim made by T1.

Our professional development approach based on modeling argumentation practices in teachers' learning yielded understanding of professional development as an empowering tool in learning in a personal manner:

T1: We've had a theme, a goal. We knew what we were striving for and I think that's very important for your professional development. If you know what the end product, the objective is, much like the kids really, then you can drive yourself to the end. I often feel with professional development days, sessions, it's very waffly and you have no idea. You feel, that wasn't personalised for me. I think what this project has done is it made it personal for each one of us.

T2: That comes from the fact that we chose what we were going to do. In terms of a brief, it was a very open brief. To be honest, we were a bit like.. right! What do we do now? Then we sort of discussed what classes we shared together. We asked what do we do together? So that was the initial collaboration to begin with.

T1: What concerns do we have.

T2: What problems do we have? We discussed our classes and suddenly it started fitting in together because we came up with it not, because we were prescribed with something to do.

Teachers also penceived professional development as something that they could have ownership about, rather than being imposed on them:

"It has kind of opened up our eyes to the fact that professional development obviously isn't just going out on a course. Like professional development is something that you can do for yourself if you're given the time. So for example, you know for us we feel our professional development has stemmed from us working together and pulling ideas from each other and exploiting if you like everybody's strong points."

\section{Conclusions \& Discussion}

The paper briefly reviewed the key rationales and approaches for supporting teaching, learning and professional development in the context of argumentation with examples from food science. Challenging traditional approaches to food science to be inclusive of evidencebased reasoning is likely to improve understanding as well as the skills of argument. Conventional topics can be situated in task structures that, by design, appeal to competing theories, explanations and claims, and reinforce appeals to evidence and justifications. Teachers who are expected to work with pupils on such tasks will not suddently change the way that they have always taught food science. They will need to be supported through professional development in order to internalise and appropriate argumentation as a 
meaningful strategy, and to have a sense of ownership. Mixing food science with argumentation, then, demands more than just an addition or a 'stir'. It requires a fundamendal 'shake' to ensure an approach that nurtures evidence-based reasoning as a habit of mind.

\section{References}

Erduran, S. (2012). The role of dialogue and argumentation. In J . Oversby (Ed.), Guide to Research in Science Education (pp. 106- 116). Hatfield: Association for Science Education.

Erduran, S., \& J iménez-Aleixandre, J . M. (2012). Research on argumentation in science education in Europe. In D. J orde \&J . Dillon (Eds.), Science Education Research and Practice in Europe: Retrospective and Prospective (pp. 253-289). Rotterdam: Sense Publishers.

Erduran, S., \&J iménez-Aleixandre, M. P. (Eds.) (2008). Argumentation in science education. Perspectives from classroom-based research. Dordrecht: Springer.

Erduran, S., \& Pabuccu, A. (2012). Bonding chemistry and argument: supporting the teaching and learning of argumentation through chemistry stories. Teacher and Student Resource. Bristol: University of Bristol. Retrieved from http:// www.bristol.ac.uk/ education/ news/ 2012/ 63.html

Erduran, S., Simon, S., \&Osborne, J . (2004). TAPping into argumentation: Developments in the use of Toulmin's Argument Pattern in studying science discourse. Science Education, 88(6), 915933.

Erduran, S., \&Yan, X. (Eds). (2009). Minding gaps in argument: supporting the teaching of scientific inquiry. Booklet and DVD. Bristol: University of Bristol.

Erduran, S., Yee, W. C., \&Ingram, N. (2011). Assessment and Practical Inquiry in Scientific Argumentation. Website of CPD and Teaching/Learning Resources. Retrieved from http:// www.apisa.co.uk

J ames Bond: 10 facts about Bond and drink. (2012, April 4). The Telegraph.

Kuhn, D. (1993). Science as argument: Implications for teaching and learning scientific thinking. Science Education, 77, 319- 337.

La Velle, B. L., \&Erduran, S. (2007). Argument and developments in the science curriculum. School Science Review, 88(324), 31-40.

Ozdem, Y., Cakiroglu, J ., Ertepinar, H., \&Erduran, S. (in press). The nature of pre-service science teachers' argumentation in inquiry-oriented laboratory context. International J ournal of Science Education.

Perelman, C., \&Olbrechts-Tyteca, L. (1969). The new rhetoric: A treatise on argumentation. Notre Dame: University of Notre Dame Press. (Original work published 1958).

Suppovitz, J . A., \&Turner, H. M. (2000). The effects of professional development on science teaching practices and classroom cultures. J ournal of Research in Science Teaching, 37(9), 963-980.

Toulmin, S. (1958). The Uses of Argument. Cambridge: Cambridge University Press.

van Eemeren, F.H., Grootendorst, R., Henkemans, F.S., Blair, J .A., J ohnson, R.H., Krabbe, E.C.W., ... Zarefsky, D. (1996). Fundamentals of argumentation theory: A handbook of historical backgrounds and contemporary developments. Mahwah, NJ : Lawrence Erlbaum Associates.

Walton, D. N. (1996). Argumentation schemes for presumptive reasoning. Mahwah, NJ : Lawrence Erlbaum Associates. 